\title{
Markers of peripheral perfusion during high-flow regional cerebral perfusion for aortic arch repair
}

\author{
Koichi Sughimoto, MD, PhD, ${ }^{\text {a,b }}$ Satoshi Kohira, PhD, ${ }^{\text {a }}$ Hidenori Hayashi, MD, ${ }^{\text {a }}$ Shinzo Torii, MD, PhD, ${ }^{\text {a }}$ \\ Tadashi Kitamura, MD, PhD, ${ }^{a}$ Tetsuya Horai, $\mathrm{MD}, \mathrm{PhD},{ }^{\mathrm{a}}$ and Kagami Miyaji, $\mathrm{MD}, \mathrm{PhD}^{\mathrm{a}}$
}

\section{ABSTRACT}

Objectives: High-flow regional cerebral perfusion (HFRCP) provides cerebral and somatic oxygen delivery through collateral vessels during aortic arch repair in small children; however, optimal flow conditions during HFRCP have not been established. We sought to identify markers of peripheral perfusion during HFRCP.

Methods: Between 2009 and 2016, in total 20 consecutive pediatric patients undergoing aortic arch repair with HFRCP were enrolled in this prospective, observational study. Median age was 20 days (range, 6-116 days); median body weight was $2.77 \mathrm{~kg}$ (range, $1.8-4.98 \mathrm{~kg})$. Oxygen delivery ratio $\left(\mathrm{Do}_{2} \mathrm{R}\right)$ was calculated as the oxygen delivery during HFRCP divided by the oxygen delivery before HFRCP. Regional oxygen saturations on the forehead and on the thigh $\left(\mathrm{rSo}_{2} \mathrm{~T}\right)$ were monitored during HFRCP, and postoperative creatinine kinase and lactate concentrations were measured as postoperative outcomes. Multivariate analyses were performed to clarify the effectiveness of $\mathrm{Do}_{2} \mathrm{R}$ and $\mathrm{rSO}_{2} \mathrm{~T}$ as markers of peripheral perfusion during HFRCP.

Results: No deaths or neurologic impairments occurred. Multivariate analysis showed that the lowest $\operatorname{rSo}_{2} \mathrm{~T}(P=.005)$ and cardiopulmonary bypass time $(P=.012)$ predicted postoperative creatinine kinase concentration. $\mathrm{Do}_{2} \mathrm{R}$ was the only factor to predict postoperative lactate concentration $(P<.001)$. Receiver operating characteristic analysis showed that $\mathrm{Do}_{2} \mathrm{R}$ less than 0.66 predicted risk of high postoperative lactate concentration $(>5.0 \mathrm{mmol} / \mathrm{L})$, with area under the curve of 0.95 .

Conclusions: For aortic arch repair in small children, $\mathrm{rSo}_{2} \mathrm{~T}$ and $\mathrm{Do}_{2} \mathrm{R}$ during HFRCP are useful markers for predicting peripheral perfusion. Maintaining higher $\mathrm{Do}_{2} \mathrm{R}$ during HFRCP minimizes postoperative increases in lactate and creatinine kinase concentrations. (J Thorac Cardiovasc Surg 2018;156:2251-7)

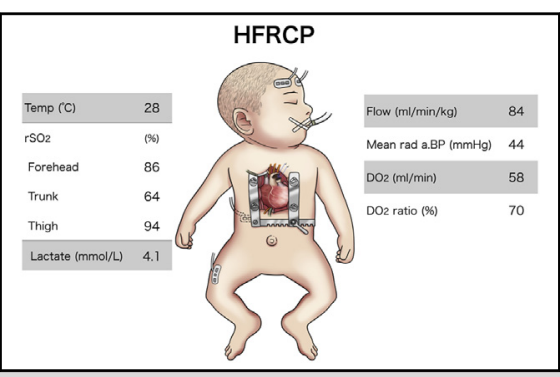

In this example, regional oxygen saturations were maintained during HFRCP.

\section{Central Message}

Flow during high-flow regional cerebral perfusion in aortic arch repair for small children can be optimized by closely monitoring the oxygen delivery ratio and regional oxygen saturation on the thigh.

\section{Perspective}

The optimal flow conditions of cardiopulmonary bypass during high-flow regional cerebral perfusion (HFRCP) in aortic arch repair for small children remain unclarified. We propose the oxygen delivery ratio $\left(\mathrm{Do}_{2} \mathrm{R}\right)$ as a new reliable marker. $\mathrm{Do}_{2} \mathrm{R}$ is calculated as oxygen delivery during HFRCP divided by that before HFRCP. $\mathrm{Do}_{2} \mathrm{R}$ greater than $70 \%$ during HFRCP is associated with maintained peripheral perfusion.

See Editorial Commentary page 2258
High-flow regional cerebral perfusion (HFRCP), defined as a flow greater than $70 \mathrm{~mL} / \mathrm{min} / \mathrm{kg}$, is an effective and useful adjunct to the Norwood procedure and repairs of coarctation of the aorta or aortic arch interruption, enabling the delivery of maintained cerebral and somatic oxygen through collateral vessels during aortic arch repair in neonates and small infants. ${ }^{1,2}$ Our previous research demonstrated that regional cerebral perfusion flow is correlated with somatic

\footnotetext{
From the ${ }^{\mathrm{a} D e p a r t m e n t}$ of Cardiovascular Surgery, School of Medicine, Kitasato University, Sagamihara, Japan; and ${ }^{\mathrm{b}}$ Mazankowski Alberta Heart Institute,

Edmonton, Alberta, Canada.

No funds were received specifically for this study.

Received for publication Nov 10, 2017; revisions received Aug 6, 2018; accepted for publication Aug 13, 2018.
}

regional oxygen saturation $\left(\mathrm{rSO}_{2}\right)$, and inversely correlated with an increase in lactate concentration. ${ }^{2}$ Optimal flow during HFRCP and sensitive markers of adequate somatic perfusion, however, have not been established. We therefore sought to identify markers of adequate peripheral perfusion during HFRCP by comparing $\mathrm{rSO}_{2}$ on the trunk versus $\mathrm{rSO}_{2}$ on the thigh and by evaluating the correlation between oxygen delivery $\left(\mathrm{DO}_{2}\right)$ and the level of lactate. A further aim of

\footnotetext{
Address for reprints: Koichi Sughimoto, MD, PhD, Department of Cardiovascula Surgery, Kitasato University School of Medicine, 1-15-1 Kitasato, Minami-ku, Sagamihara 252-0375, Japan (E-mail: ksughimoto@gmail.com). $0022-5223 / \$ 36.00$

Copyright $@ 2018$ Published by Elsevier Inc. on behalf of The American Association for Thoracic Surgery

https://doi.org/10.1016/j.jtcvs.2018.08.097
} 


\section{Abbreviations and Acronyms \\ HFRCP $=$ high-flow regional cerebral perfusion \\ $\mathrm{rSO}_{2} \quad=$ regional oxygen saturation \\ $\mathrm{Do}_{2} \quad=$ oxygen delivery \\ $\mathrm{CO}=$ cardiac output \\ $\mathrm{CPB}=$ cardiopulmonary bypass \\ $\mathrm{SO}_{2}=$ hemoglobin oxygen saturation \\ $\mathrm{Do}_{2} \mathrm{R}=$ oxygen delivery ratio \\ $\mathrm{CK}=$ creatinine kinase \\ $\mathrm{CK}-\mathrm{MB}=$ creatinine kinase myoglobin-binding isoenzyme \\ $\mathrm{RBC}=$ red blood cell \\ $\mathrm{ICU}=$ intensive care unit \\ IQR = interquartile range}

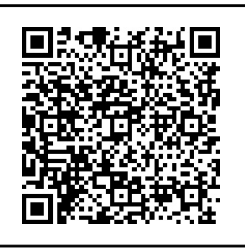

this pilot study was to measure the chronologic changes in somatic and cerebral $\mathrm{rSO}_{2}$ to evaluate the adequacy of somatic perfusion during HFRCP.

\section{METHODS \\ Patients}

From August 2013 to February 2016, a total of 20 consecutive neonates and infants (18 boys and 2 girls) with median age of 20 days (range, 6-116 days) and a median body weight of $2.77 \mathrm{~kg}$ (range, 1.8-4.98 kg) were enrolled in this prospective, observational study. The institutional review board approved the study and the collection of associated clinical physiologic data, and informed consent was obtained from the parents or guardians of all participating patients. All participants underwent arch reconstruction with HFRCP for either coarctation of the aorta $(n=18)$ or interruption of the aortic arch (type $A, n=2$ ). Patients with univentricular circulation were excluded. Other associated diagnoses included ventricular septal defects $(n=13)$, atrial septal defects $(n=18)$, complete atrioventricular septal defect $(n=1)$, and supracardiac type total anomalous pulmonary venous drainage $(\mathrm{n}=1)$. Three patients had Down syndrome (Table 1). All patients underwent aortic arch repair as their initial procedure, except for a patient who had undergone bilateral pulmonary artery banding before aortic arch repair.

\section{Data Measurement}

The $\mathrm{rSO}_{2}$ values on both sides of the forehead, trunk, and thigh were monitored intraoperatively with near-infrared spectroscopy (INVOS 5100; Somanetics, Troy, Mich). The bilateral frontal cerebral $\mathrm{rSO}_{2}$ values were measured and compared during the surgery.

$\mathrm{DO}_{2}$ was calculated as follows: $\mathrm{Do}_{2}=\mathrm{CO} \times\left[1.39 \times \mathrm{Hb} \times \mathrm{So}_{2}+\right.$ $\left.\left(0.003 \times \mathrm{PaO}_{2}\right)\right]$, where $\mathrm{CO}$ (cardiac output, in $\left.\mathrm{L} / \mathrm{min}\right)$ is the total flow generated by cardiopulmonary bypass (CPB), $H b$ is the hemoglobin concentration, and $\mathrm{SO}_{2}$ is the hemoglobin oxygen saturation expressed as a fraction $(\%)$. The $\mathrm{Do}_{2}$ ratio $\left(\mathrm{Do}_{2} \mathrm{R}\right)$ was defined as the quotient of $\mathrm{Do}_{2}$ during HFRCP divided by the $\mathrm{Do}_{2}$ before HFRCP (Figure 1).
TABLE 1. Patient characteristics

\begin{tabular}{lc}
\hline Age (d) & \\
Median & 20 \\
Range & $6-116$ \\
Body weight (kg) & \\
$\quad$ Median & 2.77 \\
Range & $1.8-4.98$ \\
Sex (female/male) & $2: 18$ \\
Diagnosis & \\
Coarctation of aorta & 18 \\
Interruption of aortic arch (type A) & 2 \\
Associated diagnosis & \\
ASD & 13 \\
VSD & 18 \\
Complete AVSD & 1 \\
TAPVD supracardiac & 1 \\
Down syndrome & 3 \\
\hline
\end{tabular}

$\overline{A S D \text {, Atrial septal defect; } V S D \text {, ventricular septal defect; } A V S D \text {, atrioventricular }}$ septal defect; TAPVD, total anomalous pulmonary venous drainage.

To investigate the optimal flow condition during HFRCP, we sought correlations between $\mathrm{rSO}_{2}, \mathrm{Do}_{2} \mathrm{R}$, and other postoperative markers of peripheral perfusion, such as creatinine kinase (CK) and lactate dehydrogenase. The concentrations of alanine transaminase, aspartate transaminase, blood urea nitrogen, $\mathrm{C}$-reactive protein, and lactate were also measured in the perioperative period. CK myoglobin-binding isoenzyme (CK-MB) was measured when considered necessary. Data sampling was conducted before the operation, during cooling, during HFRCP, during rewarming, at the time of cessation of $\mathrm{CPB}$, at admission to the intensive care unit (ICU), and 12 hours after admission to the ICU.

\section{Surgery and Cardiopulmonary Bypass System}

The technique for performing CPB and management during this procedure have been reported previously (Video 1$) \cdot{ }^{1-3}$ Before commencement of CPB, a 3.5-mm GORE-TEX tube (W. L. Gore \& Associates, Flagstaff, Ariz) was anastomosed to the right innominate artery with a side-clamp and connected to the aortic cannula, after which the CPB was established between this aortic cannula and bicaval cannulations. The CPB system in all cases consisted of a distant roller pump, a remote-controlled unit (HAS-2; Senko Medical, Tokyo, Japan), a low-prime oxygenator, and a reservoir (priming volume $43 \mathrm{~mL}$, Baby-FX; Terumo, Tokyo, Japan). The extracorporeal circuit tubing was selected in accordance with each patient's body weight. The priming volume of the tubing was $120 \mathrm{~mL}$ for patients weighing $6 \mathrm{~kg}$ or less. Blood gas balance was managed with the $\mathrm{pH}$-stat strategy. Total circulatory arrest with deep hypothermia was not implemented; instead, systemic perfusion was maintained by using HFRCP under moderate hypothermia $\left(28^{\circ} \mathrm{C}-30^{\circ} \mathrm{C}\right)$. Isosorbide dinitrate $(2.0 \mu \mathrm{g} / \mathrm{kg} / \mathrm{min})$ and chlorpromazine $(3.0 \mathrm{mg} / \mathrm{kg})$ were administered during $\mathrm{CPB}$ to enhance collateral perfusion to the lower body. The conditions of flow during CPB are summarized in Table 2. After the neck vessels and descending aorta were clamped, aortic arch repair was performed with HFRCP. Pump flow was initially targeted at around $150 \mathrm{~mL} / \mathrm{kg} / \mathrm{min}$ and then lowered during HFRCP, with adjustments made in accordance with the $\mathrm{rSO}_{2}$ and blood gas data. The $\mathrm{PaO}_{2}$ during HFRCP was targeted at $250 \mathrm{~mm} \mathrm{Hg}$. The mean radial artery pressure was maintained at 35 to $45 \mathrm{~mm} \mathrm{Hg}$ during the total bypass, and the maximal targeted radial artery pressure was then $45 \mathrm{~mm} \mathrm{Hg}$ during HFRCP. The lower body temperature was controlled at around $28^{\circ} \mathrm{C}$ during HFRCP. Cardioplegic solution $(10 \mathrm{~mL} / \mathrm{kg}$ ) was given every 20 minutes. After termination of $\mathrm{CPB}$, modified ultrafiltration was performed with a polymethyl methacrylate hemofilter in all patients. After administration of the first cardioplegia, ductal tissue was excised, and an end-to-side anastomosis was performed for the arch repair. During CPB, the mixed venous 


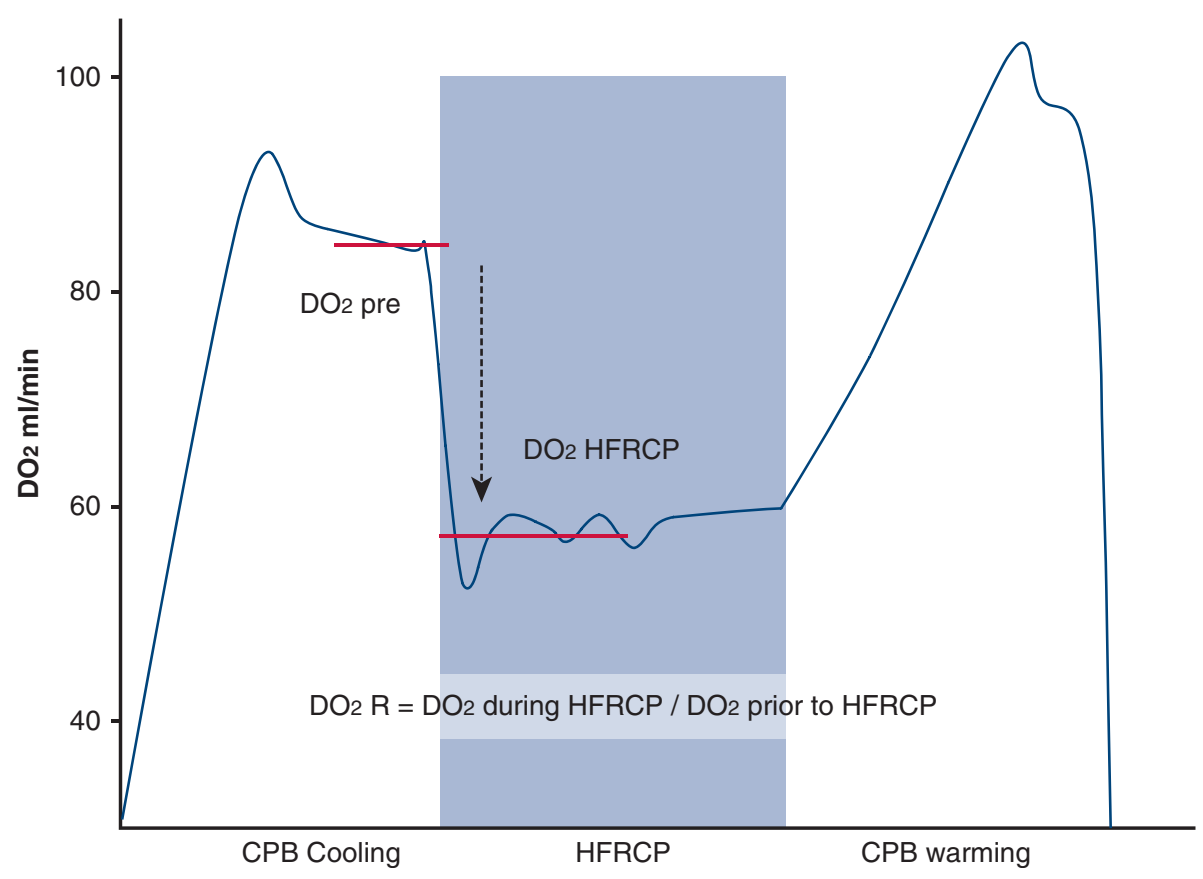

FIGURE 1. Example of oxygen delivery $\left(D_{2}\right)$ during cardiopulmonary bypass $(C P B)$ and high-flow regional cerebral perfusion $(H F R C P)$.

oxygen saturation and the $\mathrm{rSO}_{2} \mathrm{~s}$ were maintained at greater than $70 \%$ and $50 \%$, respectively. Heparinization was neutralized by protamine sulfate until the activated coagulation time had normalized.

\section{RBC Transfusion}

The minimum number of units of red blood cells (RBCs) to prevent hyperkalemia was transfused. RBCs were transfused during CPB to patients in whom the required mixed venous and regional tissue oxygen saturations could not be maintained by increasing the pump flow and fraction of inspired oxygen and increasing the hematocrit to $27 \%$ to $30 \%$. The packs of RBCs were passed through a potassium adsorption filter (Kawasumi KPF-4; Kawasumi Laboratories, Tokyo, Japan) before administration to reduce the amount of potassium infused with the RBCs.

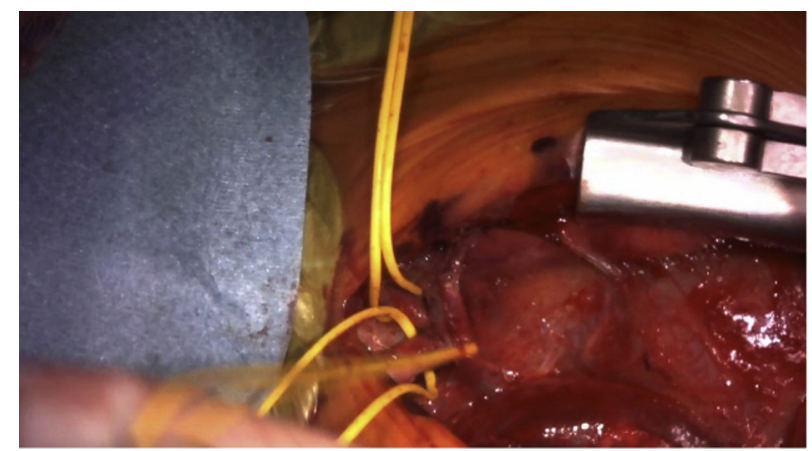

VIDEO 1. The concept and procedure of high-flow regional cerebral perfusion (HFRCP) are explained. The flow condition, chronologic changes of regional oxygen saturation $\left(\mathrm{rSO}_{2}\right)$ in different locations, lactate level, and oxygen delivery $\left(\mathrm{Do}_{2}\right)$ are demonstrated. $\mathrm{CPB}$, Cardiopulmonary bypass; $e P T F E$, expanded polytetrafluoroethylene; rad $a . B P$, radial artery blood pressure. Video available at: https://www.jtcvs.org/article/S00225223(18)32492-9/fulltext.

\section{Statistical Analyses}

Statistical analyses were performed with XLSTAT software (version 19.03; Addinsoft SARL, Paris, France). Continuous variables are presented as the median and interquartile range (IQR) for skewed distributions or as the mean \pm SD for normally distributed variables. Patient follow-up was $100 \%$ for the corresponding patients. Multivariate linear regression modeling was used to determine which variables were associated with increases in lactate and CK concentrations. Patient characteristics and perioperative factors were included in the multivariate regression. The goodness of fit of the model was expressed by the determination coefficient $(R)$. The optimal cutoff value of $\mathrm{Do}_{2} \mathrm{R}$ with the highest combination of sensitivity and specificity for postoperative high level of lactate was determined with the receiver operating characteristic curve.

\section{RESULTS}

The sternum was closed at the end of surgery in all patients. Median duration of intubation was 7 days (IQR, 6-9 days), and median ICU stay was 13.5 days (range, 6-32 days). One patient required a tracheostomy and a gastrostomy tube because of recurrent nerve paralysis. No patient required peritoneal dialysis or dialysis filtration support. There were no operative or in-hospital deaths, and there were no deaths during a mean follow-up period of $3.2 \pm 2.3$ years. There was no neurologic impairment in any case. All patients were discharged from the hospital without major complications.

\section{CPB Conditions and Intraoperative and Postoperative Measurements}

The CPB time, crossclamping time, duration of clamping of the descending aorta, flow during $\mathrm{CPB}$, flow during HFRCP, and pressure in the radial artery during HFRCP are summarized in Table 2. 
TABLE 2. Perioperative variables

\begin{tabular}{|c|c|c|}
\hline Variables & Median & IQR \\
\hline CPB time (min) & 133.5 & $114-180$ \\
\hline Total bypass time (min) & 86.4 & $65-99$ \\
\hline Crossclamp time (min) & 58.5 & $51-72$ \\
\hline $\begin{array}{l}\text { Descending aorta clamp } \\
\text { time (min) }\end{array}$ & 37.0 & $30-45$ \\
\hline Lowest temperature $\left({ }^{\circ} \mathrm{C}\right)$ & 28.0 & $28-29.2$ \\
\hline $\begin{array}{l}\text { CPB flow } \\
\text { Raw (mL/min) } \\
\text { Indexed }(\mathrm{mL} / \mathrm{min} / \mathrm{kg})\end{array}$ & $\begin{array}{l}395.5 \\
136.0\end{array}$ & $\begin{array}{l}325-437.5 \\
127-145.1\end{array}$ \\
\hline $\begin{array}{l}\text { Flow during RCP } \\
\text { Raw (mL/min) } \\
\text { Indexed }(\mathrm{mL} / \mathrm{min} / \mathrm{kg})\end{array}$ & $\begin{array}{r}264.0 \\
83.6\end{array}$ & $\begin{array}{l}202.5-311 \\
71.6-102.8\end{array}$ \\
\hline Flow ratio $\mathrm{RCP} /$ non-RCP & 0.66 & $0.57-73$ \\
\hline $\begin{array}{l}\text { Systemic BP during } \\
\text { RCP }(\mathrm{mm} \mathrm{Hg})\end{array}$ & 43.5 & $41.5-45.3$ \\
\hline $\begin{array}{l}\text { Circuit pressure during } \\
\text { RCP (mm Hg) }\end{array}$ & 97.0 & $85.8-135$ \\
\hline $\begin{array}{l}\text { Pressure difference between } \\
\text { circuit and radial artery during } \\
\mathrm{RCP}(\mathrm{mm} \mathrm{Hg})\end{array}$ & 56.0 & $42.5-91.3$ \\
\hline \multicolumn{3}{|l|}{$\mathrm{rSO}_{2}(\%)$} \\
\hline \multicolumn{3}{|l|}{ Forehead } \\
\hline Before CPB & $65.0 \%$ & $59.5 \%-73.5 \%$ \\
\hline CPB cooling & $76.0 \%$ & $69 \%-79.3 \%$ \\
\hline RCP start & $82.5 \%$ & $77.8 \%-86.5 \%$ \\
\hline RCP average & $86.0 \%$ & $79.5 \%-88.8 \%$ \\
\hline $\mathrm{RCP}$ right-left difference & $3.4 \%$ & $-2.5 \%$ to $8.3 \%$ \\
\hline CPB rewarming & $67.0 \%$ & $60 \%-71.5 \%$ \\
\hline After CPB & $63.0 \%$ & $60 \%-68.5 \%$ \\
\hline \multicolumn{3}{|l|}{ Trunk } \\
\hline Before CPB & $74.0 \%$ & $66 \%-80 \%$ \\
\hline CPB cooling & $79.0 \%$ & $74.5 \%-81.5 \%$ \\
\hline RCP start & $78.0 \%$ & $72.5 \%-86 \%$ \\
\hline $\mathrm{RCP}$ average & $64.0 \%$ & $50 \%-78 \%$ \\
\hline $\mathrm{CPB}$ rewarming & $86.0 \%$ & $80.5 \%-90 \%$ \\
\hline After CPB & $92.0 \%$ & $85.5 \%-95 \%$ \\
\hline \multicolumn{3}{|l|}{ Thigh } \\
\hline Before CPB & $76.6 \%$ & $74 \%-79 \%$ \\
\hline CPB cooling & $93.0 \%$ & $88 \%-96 \%$ \\
\hline RCP start & $85.0 \%$ & $69-91.5 \%$ \\
\hline RCP average & $94.0 \%$ & $64.8-97.3 \% *$ \\
\hline $\mathrm{CPB}$ rewarming & $85.5 \%$ & $83.8 \%-89.3 \%$ \\
\hline After CPB & $85.0 \%$ & $77.8 \%-95 \%$ \\
\hline Hemoglobin during RCP (g/L) & 93.5 & $91-99.3$ \\
\hline \multicolumn{3}{|l|}{$\mathrm{Do}_{2}(\mathrm{~mL} / \mathrm{min})$} \\
\hline Before RCP & 87.2 & 72.3-101.2 \\
\hline During RCP & 57.9 & $42.8-72.6$ \\
\hline Ratio (\%) & 69.8 & $60.1 \%-79.2$ \\
\hline \multicolumn{3}{|l|}{$\mathrm{VO}_{2}(\mathrm{~mL} / \mathrm{min})$} \\
\hline Before RCP & 11.7 & $10.6-14$ \\
\hline
\end{tabular}

TABLE 2. Continued

\begin{tabular}{lcc}
\hline \multicolumn{1}{c}{ Variables } & Median & IQR \\
\hline During RCP & 1.5 & $0.8-3.1$ \\
Intubation period (d) & 7.0 & $6-9$ \\
PICU stay (d) & 13.5 & $6-32 \dagger$ \\
\hline
\end{tabular}

$I Q R$, Interquartile range; $C P B$, cardiopulmonary bypass; $R C P$, regional cerebral perfusion; $B P$, blood pressure; $r \mathrm{SO}_{2}$, regional oxygen saturation; $\mathrm{Do}_{2}$, oxygen delivery; $\mathrm{Vo}_{2}$, oxygen consumption; $P I C U$, pediatric intensive care unit. $* P=.01$ for comparison between trunk and thigh regional oxygen saturation during regional cerebral perfusion. $\dagger$ Total range rather than interquartile range reported.

During HFRCP, the $\mathrm{rSO}_{2}$ on the forehead increased, whereas the $\mathrm{rSO}_{2}$ on the thigh decreased and then recovered after declamping of the descending aorta (Figure 2, $A$ and $B$ ). During HFRCP, the lowest $\mathrm{rSO}_{2}$ measurements on the forehead, trunk, and thigh were $86.0 \%$ (IQR, 79.5\%-88.8\%), 64.0\% (IQR, 50\%-78\%), and $94.0 \%$ (IQR, 64.8\%-97.3\%), respectively. The truncal $\mathrm{rSO}_{2}$ was significantly lower than the thigh $\mathrm{rSO}_{2}$ $(P<.01)$. The right-sided frontal $\mathrm{rSO}_{2}$ was greater than the left-sided frontal $\mathrm{rSO}_{2}$ during HFRCP in 13 of 20 patients by $3.4 \%$ (IQR $-2.5 \%$ to $8.3 \%$ ). The perioperative measurements are shown in Table 3. On postoperative day 1 , blood urea nitrogen and $\mathrm{CK}$ rose to $14.8 \mathrm{mg} / \mathrm{dL}$ and $0.63 \mathrm{mg} / \mathrm{dL}$, respectively. Aspartate transaminase $(103 \mathrm{U} / \mathrm{L})$, lactate dehydrogenase (483.5 U/L), CK (999.5 U/L), and CK-MB (172 U/L) peaked at the time of admission to the ICU and then decreased. The highest postoperative lactate concentration was $4.9 \mathrm{mmol} / \mathrm{L}$ (IQR, 4.2-5.5 mmol/L).

\section{Multivariate Analysis and Correlation Between Lactate Concentration and $\mathrm{Do}_{2} \mathrm{R}$}

Multivariate analysis revealed that high postoperative CK concentrations were associated with prolonged $\mathrm{CPB}$ time $(P=.012)$ and nadir $\mathrm{rSO}_{2}$ on the thigh $(P=.005)$, whereas only high postoperative lactate levels were associated with $\mathrm{Do}_{2} \mathrm{R}(P<.001$; Table 4$)$. The highest postoperative lactate level was negatively correlated with $\mathrm{Do}_{2} \mathrm{R}$ $(R=0.81$; Figure $3, A$ and $B)$. On receiver operating characteristic analysis, a $\mathrm{Do}_{2} \mathrm{R}$ cutoff value of 0.66 had the largest summed sensitivity and specificity of 1.80 , comprising a sensitivity of 0.80 (95\% CI, 0.48-0.95) and a specificity of 1.00 (95\% CI, 0.67-1.00), with an area under the curve of 0.95 . This receiver operating characteristic analysis revealed that a $\mathrm{Do}_{2} \mathrm{R}$ of 0.66 or less predicted the risk of high lactate concentration $(>5.0 \mathrm{mmol} / \mathrm{L})$.

\section{DISCUSSION}

Since the evolution of regional cerebral perfusion during aortic arch repair, various modifications have contributed to improved outcomes. ${ }^{4-6}$ The advantages of HFRCP are supported by previous research that confirmed low 

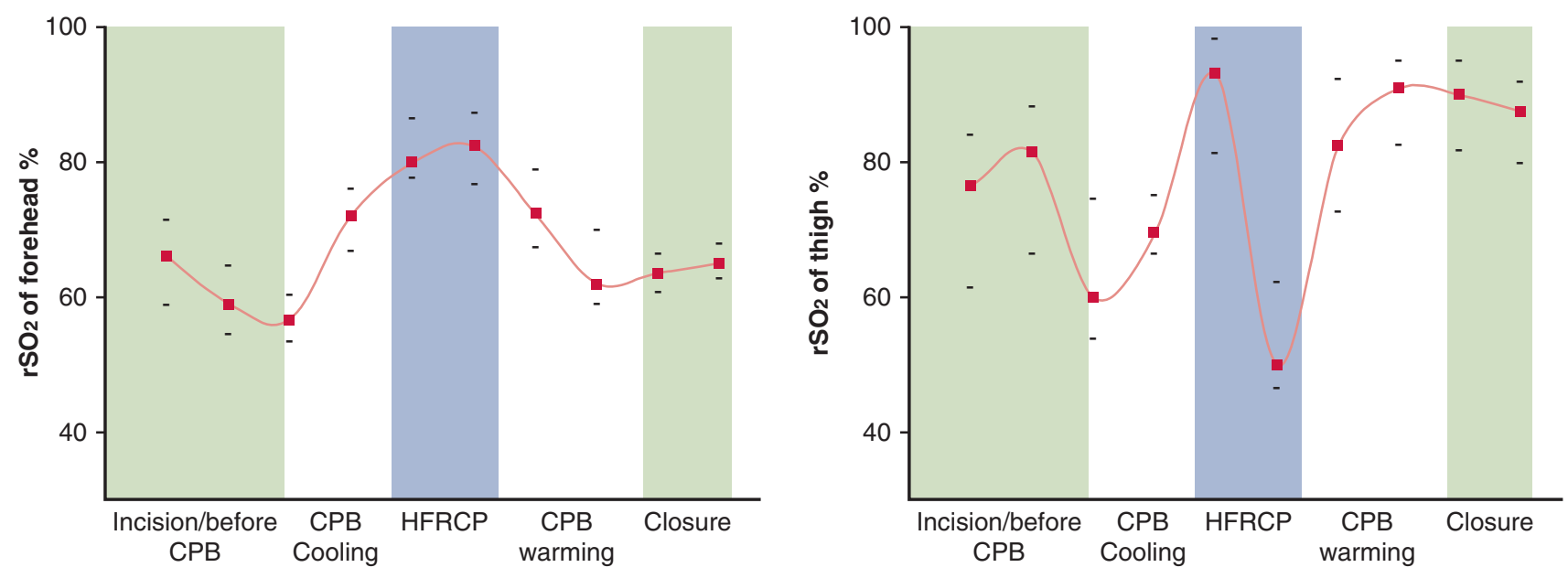

A

B

FIGURE 2. Regional oxygen saturation $\left(\mathrm{rSo}_{2}\right)$ was measured on the forehead (A) and thigh (B) before, after, and during cardiopulmonary bypass ( $C P B$ ). Values are expressed as the median and interquartile range. HFRCP, High-flow regional cerebral perfusion.

rates of adverse effects and seizures. ${ }^{7-9}$ After demonstrating the efficacy of HFRCP during aortic arch repair in previous reports, ${ }^{1,2}$ we sought to determine the optimal conditions for $\mathrm{CPB}$ flow by using criteria that are simple, feasible, and practical to use in the operating room. Although monitoring the radial artery pressure during aortic arch repair is one of the most important measurements, the radial artery pressure is an inadequately reliable marker during HFRCP. ${ }^{10}$ We therefore investigated $\mathrm{Do}_{2}$ as an alternative, because $\mathrm{Do}_{2}$ incorporates the factors of flow, hemoglobin, and dissolved oxygen content in the blood, and these values are measured and adjusted frequently during CPB. Before HFRCP, flow is gradually reduced to the anticipated level as the 2 neck vessels and descending aorta are clamped. In this study, the cutoff value for $\mathrm{Do}_{2} \mathrm{R}$ was 0.66 ; we therefore believe that a safe $\mathrm{Do}_{2} \mathrm{R}$ is $70 \%$ of the initial $\mathrm{DO}_{2}$ after stabilization of the $\mathrm{CPB} . \mathrm{Do}_{2}$ can be altered by controlling CPB flow and increasing or decreasing hemoglobin concentrations.

This study also revealed that $\mathrm{rSo}_{2}$ on the thigh was the most sensitive marker of adequate peripheral perfusion. Measuring $\mathrm{rSO}_{2}$ is a good tool with which to assess adequate tissue perfusion both during CPB and postoperatively. ${ }^{11-13}$ Berens and colleagues ${ }^{14}$ reported that it is feasible to monitor the somatic $\mathrm{rSO}_{2}$ during aortic arch repair and that somatic $\mathrm{rSO}_{2}$ dropped to lower values in neonates and infants than in adults, suggesting that younger children have less collateral vessels formation. In this study, however, the truncal $\mathrm{rSO}_{2}$ and the $\mathrm{rSO}_{2}$ on the thigh during HFRCP were $64 \%$ and $94 \%$, respectively, suggesting that collateral flow can be maintained during HFRCP.

The nadir $\mathrm{Do}_{2}$ and hypotension are reportedly associated with acute kidney injury after cardiac operations in adults. ${ }^{15}$ Furthermore, $\mathrm{Do}_{2}$ incorporates factors such as flow, perfusion pressure, and hemodilution anemia, which

TABLE 3. Measurement variables

\begin{tabular}{|c|c|c|c|c|c|c|c|c|}
\hline Variable & Preoperative & CPB cooling & RCP & CPB warming & CPB off & PICU entrance & РОН 12 & POD 1 \\
\hline Lactate $(\mathrm{mmol} / \mathrm{L})$ & $1.9(1.3-2.2)$ & $2.6(2.4-3)$ & $4.1(3.8-4.9)$ & $4.1(3.7-5.4)$ & $4.9(4.2-5.5)$ & $3.8(3.0-5.3)$ & $3.2(2.2-4.9)$ & $1.3(1-2.8)$ \\
\hline BUN (mg/dL) & $8.5(6.4-10.9)$ & & & & & $8.7(6.4-10.4)$ & & $14.9(12.3-16.5)$ \\
\hline Creatinine $(\mathrm{mg} / \mathrm{dL})$ & $0.44(0.35-0.48)$ & & & & & $0.43(0.34-0.52)$ & & $0.67(0.48-0.80)$ \\
\hline AST (U/L) & $37.5(28.3-48.3)$ & & & & & $103.0(88.8-138.3)$ & & $83.0(58.8-110.3)$ \\
\hline ALT (U/L) & $16.0(11.5-22)$ & & & & & $11.5(9-14.3)$ & & $15.5(13.5-18.3)$ \\
\hline LDH (U/L) & $322.5(306-409)$ & & & & & $483.5(403-535)$ & $437.0(365-541)$ & \\
\hline CK (U/L) & $128.5(111-200)$ & & & & & 999.5 (927-1157) & $652.0(471-927)$ & \\
\hline CK-MB (U/L)* & & & & & & $172.0(149-188)$ & $55.0(39-79)$ & \\
\hline CRP (mg/L) & & & & & & $0.06(0.03-0.11)$ & $1.76(1.36-3.22)$ & \\
\hline
\end{tabular}

Values are expressed as the median and interquartile range. $C P B$, Cardiopulmonary bypass; $R C P$, regional cerebral perfusion; $P I C U$, pediatric intensive care unit; $P O H$, postoperative hour; $P O D$, postoperative day; $B U N$, blood urea nitrogen; $A S T$, aspartate transaminase; $A L T$, alanine transaminase; $L D H$, lactate dehydrogenase; $C K$, creatinine kinase; $C K-M B$, creatinine kinase myoglobin-binding isoenzyme; $C R P, \mathrm{C}$-reactive protein. *Creatinine kinase myoglobin-binding isoenzyme was measured in 9 of 20 patients. 
TABLE 4. Multivariate analysis of increases in creatinine kinase and lactate concentrations

\begin{tabular}{|c|c|c|c|c|}
\hline & Variable & Coefficient & $95 \% \mathrm{CI}$ & $P$ value \\
\hline \multirow[t]{2}{*}{ CK (U/L) } & CPB time (min) & 4.23 & $1.06-7.45$ & .012 \\
\hline & Lowest $\mathrm{rSO}_{2}$ on thigh $(\%)$ & -23.26 & -38.68 to 7.83 & .005 \\
\hline Lactate $(\mathrm{mmol} / \mathrm{L})$ & $\mathrm{Do}_{2}$ ratio $(\%)$ & -0.11 & -0.14 to -0.07 & $<.001$ \\
\hline
\end{tabular}

$\mathrm{CI}$, Confidence interval; $\mathrm{CK}$, creatinine kinase; $\mathrm{CPB}$, cardiopulmonary bypass; $r \mathrm{SO}_{2}$, regional oxygen saturation; $\mathrm{Do}_{2}$, oxygen delivery.

are also reportedly risk factors for acute kidney injury. ${ }^{16-19}$ The nadir $\mathrm{DO}_{2}$ during CPB is also reportedly associated with serum glial fibrillary acid protein, which is a biomarker for brain injury in pediatric patients undergoing heart surgery. ${ }^{20}$ It thus makes sense to measure the $\mathrm{Do}_{2}$ during $\mathrm{CPB}$, especially in aortic arch repair. As mentioned earlier, our pump perfusion protocol for HFRCP comprises a body temperature of $28^{\circ} \mathrm{C}$, a perfusion pressure in the right radial artery of $45 \mathrm{~mm} \mathrm{Hg}$, and a hematocrit of $27 \%$ to $30 \%$. The results of this study indicate that these values are reasonable. Despite clamping of the descending aorta, none of our patients required postoperative dialysis, which confirms the adequacy of our current concept and strategy of HFRCP.

Regarding $\mathrm{rSO}_{2}$ monitoring, we stress the importance of measuring $\mathrm{rSO}_{2}$ on the thigh, because this was the most sensitive marker for peripheral perfusion during HFRCP and throughout $\mathrm{CPB}$. We monitored $\mathrm{rSO}_{2}$ throughout the operation through sensors attached to both sides of the forehead, the trunk (right back of the trunk), and both thighs (lateral aspects). Our target for $\mathrm{rSO}_{2}$ on the trunk during HFRCP and CPB was more than $50 \%$, as per a previous report. ${ }^{9}$ The $\mathrm{rSO}_{2}$ on the thigh $(94 \%)$ during HFRCP was higher than the truncal $\mathrm{rSO}_{2}(64 \%)$, revealing that there were significant differences in the $\mathrm{rSO}_{2}$ at various monitoring sites during HFRCP. This is presumably because of the differential regulation and sensitivity of the regional tissue beds in the body. The brain and kidneys are the most important organs to be monitored, because the blood flow to the brain is highly autoregulated in normal circumstances and is a high extraction site, whereas the kidneys are a lower extraction site and are controlled by sympathetic innervation systems. In contrast, the thigh is composed of relatively homologous skeletal muscle tissue and has a lower oxygen demand during the anesthesia and neuromuscular blockade. These fundamental differences may contribute to the variation in $\mathrm{rSO}_{2}$ at different monitoring sites. In addition, the advantages of multisite $\mathrm{rSO}_{2}$ monitoring include the increased security and safety of the management of blood supply and distribution during aortic arch repair and the easy manipulation of the control of blood distribution between the upper and lower portions of the body. Furthermore, especially when using our method during HFRCP, we can speculate on the degree of collateral blood flow to the lower body and major organs. It is therefore also important to monitor $\mathrm{rSO}_{2}$ on the trunk during HFRCP to maintain adequate $\mathrm{Do}_{2}$. Balancing the flow between cerebral perfusion and peripheral perfusion is of paramount importance during HFRCP; however, we mostly rely on the cerebral $\mathrm{rSO}_{2}$, because the
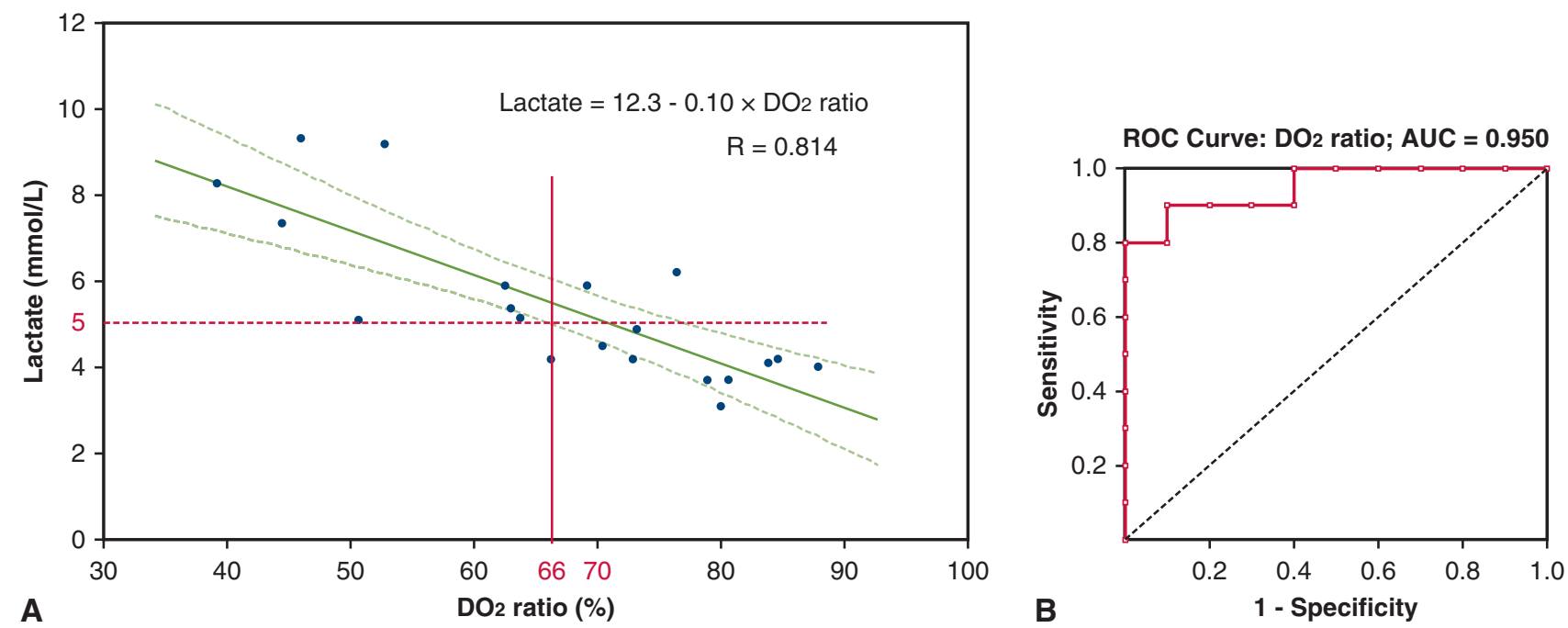

FIGURE 3. A, Correlations between the lactate concentration and oxygen delivery ratio $\left(\mathrm{Do}_{2}\right)$. B, Receiver operating characteristic $(R O C)$ curve for the oxygen delivery ratio $\left(\mathrm{Do}_{2}\right)$. AUC, Area under the curve. 
cerebral blood flow is crucial. We monitor the $\mathrm{rSO}_{2}$ to facilitate appropriate adjustment of flow conditions by adjusting flow, vasodilator, and hematocrit levels. ${\mathrm{A} \mathrm{Do}_{2} \mathrm{R} \text { of }}$ $70 \%$ will be a new target value for patients undergoing HFRCP. We also monitor the radial artery pressure as a reference to enable maintenance above the lower limit of cerebral autoregulation, as previously described. ${ }^{21} \mathrm{We}$ acknowledge, however, that flow conditions during HFRCP are variable; such variations can be related to anatomic features, such as coarctation of the aorta, interruption of the aortic arch, or other types of abnormal anatomy, or to preoperative factors such as whether the patient is stable or almost in shock. We plan to investigate these issues in further studies.

\section{CONCLUSIONS}

The $\mathrm{rSO}_{2}$ on the thigh is a very sensitive marker of peripheral perfusion during HFRCP. This pilot study demonstrates that low $\mathrm{Do}_{2} \mathrm{R}$ is associated with increased lactate concentrations, possibly indicating hypoperfusion. This method should be further studied in a larger group of patients with detailed early clinical outcomes reported.

\section{Conflict of Interest Statement}

Authors have nothing to disclose with regard to commercial support.

\section{References}

1. Miyaji K, Miyamoto T, Kohira S, Yoshii T, Itatani K, Sato H, et al. The effectiveness of high-flow regional cerebral perfusion in Norwood stage I palliation. Eur J Cardiothorac Surg. 2011;40:1215-20.

2. Miyaji K, Miyamoto T, Kohira S, Itatani K, Tomoyasu T, Inoue N, et al. Regional high-flow cerebral perfusion improves both cerebral and somatic tissue oxygenation in aortic arch repair. Ann Thorac Surg. 2010;90:593-9.

3. Miyaji K, Miyamoto T, Kohira S, Nakashima K, Inoue N, Sato H, et al. Miniaturized cardiopulmonary bypass system in neonates and small infants. Interact Cardiovasc Thorac Surg. 2008;7:75-8.

4. Asou T, Kado H, Imoto Y, Shiokawa Y, Tominaga R, Kawachi Y, et al. Selective cerebral perfusion technique during aortic arch repair in neonates. Ann Thorac Surg. 1996;61:1546-8.

5. Pigula FA, Nemoto EM, Griffith BP, Siewers RD. Regional low-flow perfusion provides cerebral circulatory support during neonatal aortic arch reconstruction. J Thorac Cardiovasc Surg. 2000;119:331-9.

6. Fraser CD Jr, Andropoulos DB. Principles of antegrade cerebral perfusion during arch reconstruction in newborns/infants. Semin Thorac Cardiovasc Surg Pediatr Card Surg Annu. 2008;61-8.

7. Andropoulos DB, Hunter JV, Nelson DP, Stayer SA, Stark AR, McKenzie ED, et al. Brain immaturity is associated with brain injury before and after neonatal cardiac surgery with high-flow bypass and cerebral oxygenation monitoring. $J$ Thorac Cardiovasc Surg. 2010;139:543-56.

8. Andropoulos DB, Mizrahi EM, Hrachovy RA, Stayer SA, Stark AR, Heinle JS, et al. Electroencephalographic seizures after neonatal cardiac surgery with highflow cardiopulmonary bypass. Anesth Analg. 2010;110:1680-5.

9. Andropoulos DB, Easley RB, Brady K, McKenzie ED, Heinle JS, Dickerson HA, et al. Neurodevelopmental outcomes after regional cerebral perfusion with neuromonitoring for neonatal aortic arch reconstruction. Ann Thorac Surg. 2013;95: 648-54; discussion 654-5.

10. Andropoulos DB, Stayer SA, McKenzie ED, Fraser CD Jr. Regional low-flow perfusion provides comparable blood flow and oxygenation to both cerebral hemispheres during neonatal aortic arch reconstruction. J Thorac Cardiovasc Surg. 2003;126:1712-7.

11. Tweddell JS, Ghanayem NS, Hoffman GM. Pro: NIRS is "standard of care" for postoperative management. Semin Thorac Cardiovasc Surg Pediatr Card Surg Аппи. 2010;13:44-50.

12. Hoffman GM, Stuth EA, Jaquiss RD, Vanderwal PL, Staudt SR, Troshynski TJ et al. Changes in cerebral and somatic oxygenation during stage 1 palliation of hypoplastic left heart syndrome using continuous regional cerebral perfusion. $J$ Thorac Cardiovasc Surg. 2004;127:223-33.

13. Hoffman GM, Ghanayem NS, Scott JP, Tweddell JS, Mitchell ME, Mussatto KA Postoperative cerebral and somatic near-infrared spectroscopy saturations and outcome in hypoplastic left heart syndrome. Ann Thorac Surg. 2017;103: $1527-35$.

14. Berens RJ, Stuth EA, Robertson FA, Jaquiss RD, Hoffman GM, Troshynski TJ, et al. Near infrared spectroscopy monitoring during pediatric aortic coarctation repair. Paediatr Anaesth. 2006;16:777-81.

15. Magruder JT, Dungan SP, Grimm JC, Harness HL, Wierschke C, Castillejo $\mathrm{S}$, et al. Nadir oxygen delivery on bypass and hypotension increase acute kidney injury risk after cardiac operations. Ann Thorac Surg. 2015; 100:1697-703

16. Xue F-S, Liu G-P, Sun C. Is nadir oxygen delivery on cardiopulmonary bypass an independent risk factor for acute kidney injury after cardiac surgery? Ann Thorac Surg. 2016;101:1631.

17. Kanji HD, Schulze CJ, Hervas-Malo M, Wang P, Ross DB, Zibdawi M, et al. Difference between pre-operative and cardiopulmonary bypass mean arterial pressure is independently associated with early cardiac surgery-associated acute kidney injury. J Cardiothorac Surg. 2010;5:71.

18. Ranucci M, Aloisio T, Carboni G, Ballotta A, Pistuddi V, Menicanti L, et al. Surgical and Clinical Outcome REsearch (SCORE) Group. Acute kidney injury and hemodilution during cardiopulmonary bypass: a changing scenario. Ann Thorac Surg. 2015;100:95-100.

19. Ranucci M, Carboni G, Cotza M, Bianchi P, Di Dedda U, Aloisio T. Surgical and Clinical Outcome Research (SCORE) Group. Hemodilution on cardiopulmonary bypass as a determinant of early postoperative hyperlactatemia. PLoS One. 2015; 10:e0126939.

20. Magruder JT, Hibino N, Collica S, Zhang H, Harness HL, Heitmiller ES, et al Association of nadir oxygen delivery on cardiopulmonary bypass with serum glial fibrillary acid protein levels in paediatric heart surgery patients. Interact Cardiovasc Thorac Surg. 2016;23:531-7.

21. Brady KM, Mytar JO, Lee JK, Cameron DE, Vricella LA, Thompson WR, et al Monitoring cerebral blood flow pressure autoregulation in pediatric patients during cardiac surgery. Stroke. 2010;41:1957-62.

Key Words: arch repair, congenital, neonate, regional cerebral perfusion 